\title{
OUTSIDERS INSIDE E INSIDERS OUTSIDE: entre a ação pública nacional e transnacional em prol dos direitos humanos ${ }^{1}$
}

\author{
Sidney Tarrow*
}

\begin{abstract}
Será que o crescimento de uma sociedade civil global é um processo cumulativo, ou estamos apenas presenciando o afloramento transnacional de uma série de Estados? Colocando essa pergunta de forma mais geral: "Será que a tradicional divisão entre políticas nacionais e internacionais está se decompondo?” Grande parte do futuro do ativismo social e transnacional depende dessa pergunta. Neste artigo, ilustrarei primeiro esse dilema referindo a história atual e conhecida: os protestos em relação à Tocha Olímpica, em Londres e Paris, e suas relações com o Tibete e Darfur, indagando o que isso nos diz em relação à natureza do ativismo transnacional público. Em seguida construirei uma tipologia de formas de interação nacional e transacional entre os atores públicos não estatais. Posteriormente, passarei a realizar uma previsão do futuro, com alguma prudência, do que alguns intitulam "sociedade civil global" e de como ela pode afetar o ativismo transnacional.

PALAVRAS-CHAVE: ativismo transnacional, movimentos sociais, sociedade civil global, política comparativa, atores públicos não-estatais.
\end{abstract}

\section{INTRODUÇÃO: um sonho para Darfur}

Em Londres, no começo de abril de 2008, houve uma série de protestos contra a passagem da Tocha Olímpica levada pelos chineses. Os protestos anteriores dos monges tibetanos e as consequentes repressões desencadearam um movimento de contestação, não somente contra a repressão da China, mas contra sua promessa hipócrita de melhorar o registro deplorável de direitos humanos, quando lhe foi concedida a sede das Olimpíadas de verão de 2008. Enquanto o patético Presidente Bush continuava tranquilamente a proclamar, de forma cada vez mais absurda, que

* Professor de Sociologia da Universidade de Cornell (Estados Unidos). $\mathrm{PhD}$ em Sociologia pela Universidade de Berkeley (Califórnia, 1965).sgt2@cornell.edu

${ }^{1}$ Uma versão anterior deste trabalho foi apresentada no Seminário de Ação Pública Governamental, na London School of Economics, de 7 a 9 de maio de 2008, e publicada no formato "On-line First", no dia 29 de janeiro de 2009 , pela Revista Internacional Human Rights Review, editada por Springer (Springer Science+Business Media). DOI 10.1007/s12142-009-0115-5. Os organizadores desse dossiê agradecem ao autor, Sidney Tarrow e a Gary Herbert, editor da Human Rights Review, pela gentil disposicão de publicar o texto e a Springer Science+Business Media por autorizar a traducão desse artigo ao português para sua difusão entre o público brasileiro.

Sou grato a Jennifer Hadden, Jude Howell, Jack Kligerman, Ken Roberts, Benita Roth, Kathryn Sikkink, Charles Tilly, Kiyoteru Tsutsui e aos participantes do seminário de as Olimpíadas não tinham ligação com a política, até Nicolas Sarkozy, Gordon Brown e o Parlamento Europeu criticaram os chineses. O que podemos aprender com esses eventos sobre os complexos vínculos transnacionais de vasto alcance no ativismo transnacional?

Alguns anos antes, Mia Farrow, atriz norteamericana do cinema, fundou uma pequena organização intitulada "Um Sonho para Darfur". Embora seu crescimento tenha sido impedido pelos esforços bem mais divulgados e com grande apoio financeiro do grupo "Salve Darfur”, Um Sonho para Darfur tinha três aspectos a seu favor:

- Em primeiro lugar, era pequena e bem ágil, para tornar-se mais eficaz do que os grupos de direitos humanos predominantes.

- Em segundo lugar, usava a Internet de forma inteligente e oportuna para divulgar sua mensagem.

- Em terceiro lugar, pôde tirar vantagem da oportunidade política oferecida pela renúncia do magnata do cinema, Steven Spielberg, como diretor artístico da Olimpíada Chinesa.

Política de Contentious Politics da Universidade de Colúmbia pelos comentários úteis na primeira versão desta palestra, os quais foram discutidos no Seminário em Colúmbia, e a Hung Jen Wang pela colaboração rápida e precisa na pesquisa. 
Um Sonho para Darfur teve um papel pequeno, porém fundamental no âmbito dos protestos da Tocha Olímpica. Segundo o International Herald Tribune:

O grupo orquestrou a coalizão de seguidores de organizações não governamentais comprometidas com o fim da violência no Sudão e também grupos comprometidos com os abusos na China: associações de atletas olímpicos, organizações comprometidas com o Tibete e com a influência da China na Birmânia; e um longo conjunto de outras causas ligadas à China (IHT, 2008, p.1).

Um Sonho para Darfur foi concebida pela ativista dos direitos humanos Jill Savitt, 40 anos, e de um pequeno grupo de jovens ativistas da Cidade de Nova York, tirando partido da fama de Mia Farrow e com o apoio financeiro de uma fundação da Califórnia, a Humanity United, apoiada pela esposa do fundador da E-Bay, Pierre Omidyar. Savitt não é diferente de milhares de jovens que escolheram estender a mão a outros que, à semelhança deles, em todo o mundo, manifestam-se contra os abusos dos direitos humanos, ou a favor do meio ambiente e dos direitos das mulheres, entre outros, enquanto trabalham no espaço nacional. Ela é o que já chamei, em outro trabalho, de "uma cosmopolita enraizada" (a rooted cosmopolitan). Citando o antropólogo Ulf Hannerz, que cunhou esse termo:

\begin{abstract}
... disperso entre os cidadãos mais comprometidos, em padrões nem sempre igualmente transparentes, encontra-se um número crescente de pessoas com vivências e ligações as mais variadas. Alguns deles podem querer redefinir a nação [...] outros, por outro lado, estão na nação, mas não fazem parte dela. Podem ser os verdadeiros cosmopolitas, ou podem ser na realidade fiéis a algum tipo de comunidade internacional imaginária [...] Também podem existir compromissos divididos, ambiguidades e repercussões conflitantes (1996, p. 90).
\end{abstract}

O mais interessante sobre Savitt e sua organização foi a capacidade, de uma só vez, de acertar num alvo (as Olimpíadas na China) como forma de fazer com que a China se juntasse às nações ocidentais e pressionasse o governo do Sudão para cessar o que ela considera políticas genocidas em Darfur. Até fevereiro, tiveram pouco êxito, em par- te devido à natureza intratável do problema de Darfur, e, em parte, devido à resistência do governo sudanês à pressão externa e pelo fato de Bejing, na realidade, não entender o "poder brando" (soft power) da ação pública não-estatal. Porém tudo isso aconteceu antes da renúncia de Spielberg e da explosão dos protestos no Tibete. O Tibete deu peso ao clamor normalmente isolado de $\mathrm{Um} \mathrm{So}$ nho para Darfur de chamar os jogos de 2008 de “as Olimpíadas Genocidas”.

Ao fundarem o Sonho para Darfur, Savitt e Mia Farrow não tinham em mente o Tibete. Também os monges tibetanos e seus defensores, que se rebelaram contra o controle da dinastia Han chinesa em março, estavam praticamente indiferentes ao Sudão. Porém as Olimpíadas ofereceram uma oportunidade política de ligar, através do tema sempre fértil do genocídio, o grupo dos monges tibetanos ao apoio dado por Beijing ao regime brutal de Khartoum no exterior. Em fevereiro, um enviado chinês visitou Darfur quatro vezes e declarou: "nós vamos convencê-los de forma direta a trabalharem com a comunidade internacional e a serem mais cooperativos".

A história de Um Sonho para Darfur e da Tocha Olímpica é incomum, porém ilustra três aspectos fundamentais de muitas campanhas transnacionais de protesto.

- Em primeiro lugar, mostra que as ações nãoestatais pequenas e específicas podem obter resultados surpreendentes em curto prazo, e que ações burocráticas semelhantes e em longa escala são muito lentas para surtir efeito.

- Em segundo lugar, mostra a importância das oportunidades políticas quase sempre fugazes, ao abrir as janelas para a ação política não-estatal.

- Em terceiro lugar, mostra como mecanismos e processos “conectados frouxamente" (loosely-coupled) podem vincular políticas nacionais e internacionais.

Antes de passar para outros exemplos dessa forma de ação transnacional e não-estatal, gostaria de esclarecer o que não vou discutir neste trabalho.

- Em primeiro lugar, não vou argumentar que os referidos eventos são o resultado da "globalização". Globalização é um termo de grande importância 
(Hall; Tarrow, 1997), porém não é uma forma adequada de questionar articulações nacionais e internacionais de interação não-estatal. As razões pelas quais penso de forma diferente devem-se ao fato de que essa interação (por exemplo, a campanha para Darfur) só se relacionava à globalização de forma distante e porque a "globalização" é indeterminada em relação ao fomento ou obstrução da ação coletiva. ${ }^{2}$

- Em segundo lugar, não vou argumentar que o poder do Estado esteja se diluindo, ou que as instituições internacionais estejam assumindo seu lugar; os leitores devem ter em mente que os Estados Unidos, recentemente, viraram o sistema internacional de cabeça para baixo com suas guerras no Iraque e no Afeganistão e devem estar bem conscientes do poder dos Estados.

- Em terceiro lugar, não vou argumentar que os movimentos sociais estão criando uma esfera inconfundível de ação civil global. Um Sonho para Darfur foi um esforço de ação pública não-estatal, baseada amplamente nos Estados Unidos. Assim também o foram a rebelião do Tibete e os protestos da Tocha Olímpica em Londres e em Paris. Se houve uma ligação, foi indireta, por intermédio da mídia, pelo poder de estruturação criativa e pela internacionalização das oportunidades políticas.

Desse modo, como é que as políticas internas e internacionais se cruzam? É ai que entra o conceito de "conexão frouxa". Com esse termo não quero dizer que os atores locais simplesmente "pensam globalmente" quando se encaixam na ação pública local. Seria uma forma muito simplista de ação pública transnacional e uma forma muito fácil de ser alcançada (Schattle, 2008; e também o capítulo 4 de Tarrow 2005). ${ }^{3} \mathrm{O}$ que, de fato, quero

2 No comentário de uma versão anterior deste trabalho, Jan Aart Scholte, um crítico nada mesquinho da globalização, propôs o rótulo "mundialização" como uma alternativa para minha noção menos abrangente de disputa transnacional. Não tenho certeza de que seja menos global do que "globalização," porém a refutação de Scholte é salutar para nos lembrar de que a disputa tem vários níveis, e não acontece unicamente entre a disputa nacional e transnacional.

3 Hans Schattle (2008) estudou uma grande amostra de materiais impressos da década de 1990 e detectou que o uso do termo "cidadania global" aumentou em mais de $350 \%$ entre 1991 e 2000. tratar é da emergência de mecanismos e processos que fazem a ponte entre as políticas nacionais e internacionais de forma sistemática, sem que sejam deslocadas ou homogeneizadas. Não significa que os Estados estejam andando inexoravelmente na direção de suas próprias dissoluções, e sim que alguns mecanismos apoiados e processos - muitos deles conflitantes - estão se desenvolvendo entre os Estados, atores não-estatais e as instituições internacionais.

No restante do trabalho, ilustrarei quatro processos de interação nacional e transnacional provenientes das pesquisas recentes na área de direitos humanos:

\begin{tabular}{c|l|l|c}
\hline \multirow{2}{*}{$\begin{array}{c}\text { Local } \\
\text { de } \\
\text { intera- } \\
\text { ção }\end{array}$} & $\begin{array}{l}\text { Nacion- } \\
\text { ais }\end{array}$ & Unidirecionais & Recíprocos \\
\cline { 2 - 4 } & $\begin{array}{l}\text { Interna- } \\
\text { cionais }\end{array}$ & Externalização & $\begin{array}{c}\text { Formação de } \\
\text { coalização dos de } \\
\text { dentro/dos de fora }\end{array}$ \\
\hline
\end{tabular}

O primeiro processo é o que denomino de internalização, ou seja, $a$ construção de campanhas de ação local ou nacional, não-estatais, construídas em torno de questões externas - a maioria das vezes de forma visível em reação às ações adotadas pelas instituições internacionais. Utilizarei as campanhas dos coreanos em prol dos direitos humanos no Japão (Tsutsui; Shin, no prelo) para ilustrar a internalização.

O segundo processo é o que eu chamo de externalização: o uso de oportunidades políticas proporcionadas por instituições internacionais, regimes ou tratados para ação de política externa. Inspirando-me em alguns trabalhos de algumas estudiosas, ilustrarei como os atores não-estatais, na Grã Bretanha, utilizaram o Tribunal de Justiça das Comunidades Européias para fazer reivindicações em relação aos seus próprios governos ou aos outros.

Oterceiro processoéo da transnacionalização da ação coletiva; com isso, refiro-me à cooperação de atores domésticos que trabalham juntos para além das fronteiras nacionais. Inspirando-me no trabalho de Richard Balme e Didier Chabanet (Chabanet, 2002; Balme; Chabanet, 2008), usarei 
o exemplo das marchas européias de desempregados para ilustrar esse processo.

O quarto processo é a formação de coalizões dos insiders e outsiders, ${ }^{4}$ termo que Kathryn Sikkink cunhou baseado em seu trabalho nas campanhas pelos direitos humanos na Argentina (2005, p. 165). Para ilustrá-lo, utilizarei o trabalho de Sally Merry sobre coalizões para combater a violência contra as mulheres na Ásia (Merry, 2006).

\section{A INTERNALIZAÇÃO DAS NORMAS DE DIREI- TOS HUMANOS}

\section{Residentes coreanos no Japão}

Os trinta e cinco anos da ocupação japonesa na Coréia deixaram um grande número de coreanos no Japão, no final da Guerra, e 600.000 deles permaneceram lá, apesar de terem conhecimento de que logo seriam destituídos da identidade japonesa (Tsutsui; Shin, 2008, p. 11), o que fez com que sofressem grandes desvantagens econômicas, sociais, legais e políticas. Para piorar a situação, a Guerra na Península da Coréia dividiu-os entre facções do Norte e do Sul. Porém, com o enfraquecimento da Guerra Fria, os residentes coreanos começaram a mobilizar-se contra a discriminação. Eles estruturaram suas campanhas de quatro formas principais: pelos direitos civis, contra a prática de impressão digital obrigatória; pela inclusão do direito ao voto dos estrangeiros, nos direitos políticos; pela participação no sistema nacional de aposentadoria, nos direitos sociais e econômicos; e pela educação étnica e pela inclusão do coreano, nos direitos culturais (p. 13).

O governo japonês demorou a reconhecer essas reivindicações. Entretanto, na medida em que o Japão se integrou mais no que os autores cha-

4 Nota do revisor: O jogo de palavras "insiders" "outsiders" significaria "os de dentro" e "os de fora". Quando utilizado, como no título, "insiders outside" e "outsiders inside" quer dizer "os de dentro fora" e "os de fora dentro". Devido a que, na última década, estendeuse consideravelmente sua utilização na literatura norteamericana e européia em inglês, e, para manter o sentido do jogo de palavras, manteremos no texto, em algumas passagens, a acepção original. mam de "sociedade mundial", houve uma maior oportunidade de pressão para o trabalho do governo (p. 9). O momento decisivo da mudança foi a ratificação de dois acordos internacionais sobre os direitos humanos no sistema da ONU e seus impactos no Japão. Segundo Tsutsui e Shin:

Os discursos globais sobre direitos humanos [...] permitiram que os residentes coreanos visualizassem seus problemas como questões de direitos universais que afetavam todos eles (p.12). [...] Em todas as quatro áreas de direitos, em algumas de forma mais eficaz do que em outras, as normas globais uniram-se ao ativismo dos residentes coreanos para produzir resultados políticos. (p. 17).

Os movimentos mais proativos surgiram na década de 1980, "quando os vocabulários de direitos humanos globais permitiram aos residentes coreanos estruturar suas reivindicações em termos de direitos humanos universais em vez de direitos especiais de cidadania" (p. 18, ênfase minha).É a internalização.

O êxito modesto dos residentes coreanos no Japão na conquista dos direitos civis, econômicos e culturais reforçou a idéia de que normas internacionais estão sendo inseridas nas políticas internas. Porém também temos o direito de questionar o esforço feito pela apropriação de vocabulários globais e pela adoção de normas internacionais de direitos humanos por um governo japonês ansioso por fazer parte novamente da comunidade das nações, apoiado por aliados influentes (o governo da Coréia do Sul e grupos de direitos humanos internacionais e pela crescente unidade dos coreanos do norte e do sul no Japão), enquanto a Guerra Fria declinava e as lembranças da guerra da Coréia retrocediam ao passado, e com o apoio externo dos ativistas internacionais. Isso nos leva ao segundo processo que quero discutir: o movimento de ativistas de dentro para fora de suas comunidades nacionais em instituições internacionais. 


\section{EXTERNALIZAÇÃO NO TRIBUNAL DE JUSTI- ÇA DAS COMUNIDADES EUROPÉIAS}

\section{Igualdade de gênero na Grã-Bretanha}

Se os coreanos, no Japão, estruturaram suas reivindicações internas em termos globais, outros grupos femininos, na Inglaterra e na Europa, têm trabalhado fora de suas comunidades políticas para reivindicar seus direitos em Luxemburgo e Estrasburgo. O Tribunal de Justiça das Comunidades Européias (TJCE) e o Tribunal de Direitos Humanos das Comunidades Européias (TDHCE) são dois dos canais mais interessantes para os atores públicos não-estatais se engajarem no ativismo externo. Eles mostram como os tribunais internacionais (embora fracos, questionados e lentos) podem funcionar como um tipo de "recife de coral" para atrair os atores sociais, cuja fraqueza, em seus países, os leva a buscar um lugar no qual seus direitos sejam reconhecidos. Vamos analisar o TJCE.

O TJCE foi inicialmente concebido como agente para evitar que os Estados-membros se insurgissem contra as políticas pactuadas. Porém, com o passar dos anos, e com a ajuda da Comissão Européia, o Tribunal conduziu a ordem jurídica da Comunidade Européia na direção supranacional, o que permitiu que os atores sociais mais fracos - como, por exemplo, as mulheres - melhorassem de forma significativa suas posições no mercado de trabalho. De 1970 até o final de 1990, 177 casos relacionados a questões das leis de igualdade de gêneros foram levadas ao Tribunal (Cichowski, 2001, p. 122).

O processo começou com a ativação do sistema legal da União Européia (UE) por uma aeromoça belga e seu advogado, em 1976. Ao completar quarenta anos, Gabrielle Defrenne, cidadã belga que trabalhava como aeromoça da empresa aérea Sabena, foi orientada a exercer outro cargo ou a perder sua posição na empresa. Depois de ter apelado sem êxito ao sistema nacional de justiça, Gabrielle Defrenne levou seu caso ao TJCE, que decidiu em seu favor, com base na igualdade de proteção, uma vez que não se aconselhava uma mudança de posição (Caporaso; Jupille, 2001).

As implicações das decisões do caso Defrenne repercutiram em toda a UE, sem falar no Reino Unido, onde o governo Thatcher continuava a se opor a que a lei do TJCE entrasse em vigor nacionalmente. Salários iguais e leis de proteção de gênero tinham sido aprovados pelo Partido Trabalhista no começo da década de 1970, porém eram bastante incompletas e continham várias exceções. O governo Thatcher trabalhou para minar até mesmo os objetivos limitados dessa legislação, ao lançar uma estratégia bloqueante no Conselho de Ministros da eu, para antecipar e selar os caminhos que poderiam levar à erosão da soberania nacional por autoridade supranacional (2001).

Porém não foi o que aconteceu. $\mathrm{O}$ caso Defrenne tornou-se a base de uma longa linha de decisões de salários iguais pelo TJCE, muitos dos quais vieram do Reino Unido e a maioria reajustava a escala feminina de salários para cima. Nesse esforço, a "Comissão de Oportunidades Iguais", juntamente com as associações de classe e com assistência externa da Comissão Européia, pressionada para desenvolver os casos que levassem o Tribunal a deter as práticas inglesas, acabou minando os Tratados da Comunidade Européia (Alter; Vargas, 2000, p. 458-459). A Comissão Européia chegou até a organizar seminários em conjunto com os sindicatos ingleses, para aconselhar os reclamantes a utilizarem as leis européias para tirar o máximo proveito (2000, p. 459).

A decisão principal surgiu em 1982, quando o Tribunal descobriu que o Reino Unido estava violando a Diretiva de Igualdade de Pagamento. O governo do Reino Unido ofereceu resistência inflexível a essa decisão, porém os resultados finais foram surpreendentes, tanto em termos da obediência do governo em relação às decisões do Tribunal (Chicowski, 2001, p. 130), quanto em relação ao compromisso com o princípio de soberania, há muito adotado, do Parlamento do Reino Unido (Caporaso; Jupille, 2001, p. 40-41). Devido à resistência de um governo que não reagia positivamente às suas demandas, os grupos de mulheres da Inglaterra utilizaram o processo de acesso 
internacional para propor suas reivindicações.É a externalização.

Porém é difícil externalizar as demandas nacionais no exterior, e seus exemplos são bem mais raros do que o visto em nosso primeiro processo (internalização), pois o fato de "ir para fora" faz com que os atores percam acesso aos recursos internos e às oportunidades que sabem como utilizar. Esse é o motivo pelo qual a maioria das externalizações acontece em ímpetos de curta direção como, por exemplo, o Fórum das ONGs de Mulheres, na Conferência das Nações Unidas em Beijing, em 1995, ou nas reuniões periódicas do Fórum Social Mundial em Porto Alegre e em outros lugares. É por esse motivo que as instituições internacionais - como o TJCE, os Tribunais Europeus e Interamericanos de Direitos Humanos e talvez no futuro, o Tribunal Internacional Criminal são importantes alvos para a externalização.

\section{TRANSNACIONALIZAÇÃO}

\section{Marchas européias contra o desemprego}

O que dizer das coalizões transnacionais de atores? É ainda mais difícil. Doug Imig e eu aprendemos como é difícil montar um conjunto de dados de eventos políticos europeus de contestação que abrangem um período de catorze anos, de 1 de janeiro de 1984 até 31 de dezembro de 1997, com base nos comunicados de imprensa da Reuters. Nesses registros, encontramos aproximadamente 9.872 relatos de eventos políticos de contestação "branda", lançados por uma ampla gama de atores sociais, a maioria deles nacionais (quase $95 \%$ do total). Os Estados ainda são os alvos predominantes de atores não-estatais.

Quanto aos 5\% restantes? Eram bimodais (como, por exemplo, o caso de questões de desigualdade de gêneros no TJCE), ou eram, na realidade, coalizões transnacionais? Ao analisá-los minuciosamente, descobrimos que 490 eventos de contestação encaixam-se em nossa definição de protesto europeu, porém somente uma percenta- gem mínima deles era transnacional: por exemplo, coalizões de atores de diferentes países europeus com metas comuns e engajados em uma ação coletiva coordenada. Quase $83 \%$ dos protestos dirigidos à UE foram considerados exemplos de internalização ou externalização de atores únicos, enquanto $17 \%$ eram transnacionais.

Deque tratavam esses eventos transnacionais? Eis alguns exemplos. Em abril de 1993, trabalhadores da Comunidade Européia fizeram greves e foram às ruas para protestar contra o fracasso de seus próprios governos em deter e reverter o aumento acentuado do desemprego. A partir de 1996, os ativistas antitransgênicos coordenaram seus esforços contra a aprovação de alimentos geneticamente modificados, e, em 1998, uma campanha importante de protesto de agricultores foi montada contra as mudanças na Política Agrícola Comum (PAC) por grupos coordenados pelas suas organizações nacionais. Além disso, com a proximidade da Cúpula de Amsterdã, grupos de mulheres organizaram campanhas para fazer lobby junto aos seus governos nacionais para apoiar uma plataforma política de igualdade de gêneros no tratado (Helfferisch; Kolb, 2001).

O Tratado de Amsterdã foi o palco de um dos eventos de protestos transnacionais mais surpreendentes na história da UE: as Marchas Européias contra o Desemprego, a Precariedade e a Exclusão Social (Chabanet, 2002). A importância não é atribuída somente ao fato de 50 mil pessoas se manifestaram contra a realização da Cúpula da UE. Como escreveram Richard Balme e Didier Chabanet, "o que fez o evento ainda mais marcante, foi a presença de manifestantes de vários países" e o fato de que as "pequenas equipes de participantes tinham cruzado a Europa para chegar aos Países Baixos" (Balme; Chabanet, 2008, p.249). É um exemplo de coalizão transnacional.

Obviamente, as diferenças nacionais de níveis de desemprego e de tradições de comportamento de protesto, que se aproximam em Amsterdã, condicionaram os que participavam ou não das marchas. O núcleo principal de participantes veio da Alemanha e da França, ambos países com altos 
índices de desemprego, tradições de proteção social e atores da sociedade civil que apoiavam a mobilização, especialmente os sindicatos e a extrema esquerda, na França, e as igrejas, na Alemanha (2008, p. 251). Em contraposição, poucos trabalhadores ingleses cruzaram o Canal da Mancha para marchar em Amsterdã, refletindo a falta de apoio das Associações dos Sindicatos e a indiferença relativa do governo inglês em relação à situação difícil dos desempregados.

Com exceção de um breve reaparecimento em 1999, as "marchas" dos desempregados foram consequentemente reduzidas ao destino de muitos movimentos transnacionais, tornando-se uma rede de comunicação na Internet, apesar de ativa. ${ }^{5}$ Não é difícil distinguir as razões. Historicamente, os desempregados são um dos grupos sociais mais difíceis de coordenar, especialmente quando moram longe uns dos outros e falam idiomas diferentes; as políticas de desemprego dos diferentes Estados-membros da UE são bastante divergentes e mostraram poucos indícios de convergência, apesar da insistência da Comunidade Européia (Balme; Chabanet, 2008, p. 224-227). Quanto à própria Comunidade Européia, os tratados fazem apenas uma ligeira ponderação em relação ao desemprego, com exceção das tentativas periódicas de identificar as melhores práticas e pôr em evidência estruturas para combatê-lo (2008, p. 218-31). ${ }^{6}$

Naturalmente, as políticas de garantias (como os subsídios regionais que se tornaram o segundo maior item do orçamento da UE) geram novos empregos nas regiões periféricas (Balme; Chabanet, 2008, cap. 6); porém essas políticas tratam cada região separadamente e estimulam a concorrência, em vez da coordenação entre regiões com as taxas mais altas de desemprego. Assim sendo, mesmo na UE - onde a internalização foi mais além -, é difícil organizar e manter a ação coletiva nacional

${ }^{5}$ Disponível em: www.euromarches.org. Vide também Royall, 2002.

${ }^{6}$ Evidentemente, as marchas não são a única forma que a ação transnacional coletiva pode assumir. Um exemplo sã̃o os Fóruns Sociais Europeus (FSE). O segundo FSE, realizado em Paris, em novembro de 2003, contou com a participação significativa da parte dos "les sans" - literalmente, "os sem". Vide Giraud, Garcia, Mouchard e Yon (2005). que se depara com mudança de metas, e é difícil mantê-la. Esse é o motivo pelo qual o quarto processo - as coalizões dos insiders/ outsiders, que foram estudadas por Kathryn Sikkink na Argentina-é tão importante.

\section{COALIZÕES DE INSIDERS / OUTSIDERS}

\section{Avanço dos direitos das mulheres na Ásia}

Seguindo a linha de pesquisa iniciada com seu importante trabalho, em cooperação com Margaret Keck, em 1990 (Keck; Sikkink, 1998), Sikkink identificou o que intitulou de "insiders/ outsiders coalition", que ocorre quando as oportunidades nacionais e internacionais estão relativamente abertas, e "ativistas nacionais privilegiam as oportunidades políticas nacionais, porém mantêm o ativismo internacional como opção complementar e compensatória”. A mudança política doméstica está mais próxima do lar e aborda mais diretamente os problemas com os quais os ativistas se deparam, de forma que concentram aí sua atenção. Entretanto, ela escreve: "os ativistas que aprenderam como usar as instituições internacionais [...] vão preservar este caminho livre em caso de necessidade" (2005, p. 64-65).

Sikkink mostra como os grupos de direitos humanos na Argentina, que mantiveram essas conexões durante a ditadura, deixaram-nas na reserva quando novas oportunidades nacionais se abriram, e formaram novas coalizões transnacionais para fomentar novas metas no âmbito doméstico (p. 166). Na dependência das instituições internacionais e de aliados transnacionais como locais básicos na luta contra os abusos de direitos humanos na Argentina, os ativistas nacionais transferiram proporcionalmente suas lutas ao âmbito doméstico, porém continuaram a utilizar seus aliados como parceiros externos em coalizões de insiders/outsiders.

Embora Sally Merry não utilize o termo "insiders/outsiders coalition", seus achados sobre as campanhas, cujos alvos são a violência contra 
as mulheres, resultam em bons exemplos do processo descrito por Sikkink. O progressivo peso no sistema da UE no combate à violência contra as mulheres não pode ser considerado um resultado da externalização. Embora a UE - o maior local do progresso do Tratado sobre Direitos Humanos garanta a muitas ONGs o status consultivo, o trabalho dos representantes das ONGs é altamente limitado aos lobbies e reuniões da UE, sendo-lhes frequentemente até negado o direito de falar nas assembléias. Além disso, os ativistas nacionais do Sul têm de superar diferenças consideráveis de escassez de recursos, até mesmo para participar dos eventos da UE, não somente devido às despesas e à distância em questão, mas pelo fato de que as ONGs, normalmente grandes e com base no Norte, possuem status diferenciados.

De modo inverso, a luta contra a violência sobre as mulheres, em todo o Sul, teria feito pouco progresso contra os grupos dominantes de homens e o emprego de interpretações "culturais" (Merry, 2006, p. 92-98), se não tivessem sido formadas coalizões de insiders/outsiders. Merry argumenta que a "Convenção sobre a Eliminação de Todas as Formas de Discriminação Contra as Mulheres" (conhecido como CEDAW, por suas siglas em inglês), muito semelhante à lei nacional, trabalha pela "produção cultural de normas" (p. 89). Adotada pela Assembléia Geral em 1979, a dita Convenção deu origem a um lento e complexo conjunto de procedimentos relacionados com relatórios dos países, audiências das comissões em Genebra e tentativas de escapar da vigilância por parte dos Estados recalcitrantes. ${ }^{7}$

Entretanto, as ONGs realmente têm efeito indireto nessas conferências globais. Conforme plasmado por Merry em suas entrevistas, "a maioria dos observadores do processo concorda que são as ONGs que suscitaram novas questões, fazem pesquisa para desenvolvê-las, conseguem

Merry relata que, em 2000, havia 242 relatórios atrasados a serem entregues à CEDAW, referentes ao tratado por 165 estados-partido. Geralmente, 78 \% dos estadospartido tinham relatórios vencidos, muitos arquivaram relatórios superficiais e alguns nem chegaram a enviar representantes aos encontros. Vide Merry (2006, p.87 88) em relação a esses achados. apoio público, e alcançam a mídia” (Merry, 2006, p. 69). O papel das ONGs de mulheres também parece estar crescendo nas últimas décadas. No encontro Beijing +5, em 2000, por exemplo:

Foram preparados no mínimo 112 relatórios alternativos avaliando a complacência de seus países com a Plataforma para Ação [...] organizaram duas sessões durante todo o dia e [...] ofereceram orientação sobre o sistema da União Européia e instruçõ̃es para lobbying. Apesar da indisposição do governo, o sistema de direitos humanos depende das atividades das ONGs (p. 70-71).

Entretanto, o papel mais significativo desses atores ainda ocorre no nível nacional. Embora os governos consigam escapar da supervisão por intermédio do sistema CEDAW, “eles enfrentam a pressão interna das ONGs, que podem receber o apoio de doadores internacionais e manterem-se ativas, mesmo se o país não dispuser de recursos suficientes para apoiá-las [...] Foram basicamente as ONGs nacionais que utilizaram as audiências para exercer pressão em seus governos para cumpri-las” (p. 88). Esses são exemplos de coalizões de insiders/outsiders.

\section{CONCLUSÕES: a conexão por intermediação}

Gostaria de concluir as observações sobre as interações nacionais e internacionais de ação pública não-estatal.

Primeiro argumentei que a globalização não é o melhor ponto de partida, pois muitas dessas interações têm pouco ou quase nada a ver com globalização. Em seguida, fui contrário às teses de oposição, que acham que a internacionalização está deslocando a autonomia nacional, ou que os grandes Estados (e especialmente um) tiveram êxito ao impor seus pontos de vista ao restante do mundo. Adoto uma abordagem mais modesta: a de que se pode observar um conjunto de conexões frouxamente ligadas em muitas áreas de interação nacional e internacional. Interpretei quatro processos de interação internacional interna, pela interseção das duas variáveis principais: os locais de interseção e o número de atores envolvidos. 
Dessas duas variáveis, inferi quatro processos principais: a internalização das normas internacionais, utilizando o caso dos residentes coreanos no Japão; a externalização dos atores domésticos nas reivindicações das mulheres inglesas junto ao Tribunal de Justiça das Comunidades Européias (TJCE); a transnacionalização da ação coletiva, observada nas marchas européias dos desempregados; e as coalizões de insiders/outsiders, conforme refletido nas relações entre as ONGs nacionais e o sistema CEDAW.

Nenhum desses processos mudou radicalmente o equilíbrio global, passando da política nacional à internacional, e todos eles operam dentro de instituições internacionais e de estruturas de poder nacional. Entretanto, analisados em conjunto, apresentam algumas virtudes positivas para os ativistas e defensores dos direitos humanos:

- Em primeiro lugar, traduzem as normas e práticas internacionais em políticas internas.

- Em segundo lugar, concedem aos atores nacionais a experiência de trabalhar em instituições internacionais e com aliados externos.

- E, em terceiro lugar, tanto no caso da transnacionalização quanto das coalizões de insiders/ outsiders, eles podem produzir, no mínimo, coalizões temporárias que cruzam fronteiras, o mais próximo que o mundo conseguiu chegar da criação de movimentos sociais globais.

Consideremos ainda o papel de Um Sonho para Darfur. Começou em um pequeno escritório no West Side em Manhattan, com quatro ativistas, e recebeu pouca atenção política ou da mídia. Porém, em breve espaço de tempo, reconhecendo nele um perigo para as relações públicas, a Embaixada daChina em Washington convidou Savitt para dialogar, tentando abafar o tom de "Olimpíadas Genocidas" com promessas vagas de conversar com os sudaneses. Porém, como cosmopolita enraizada, Savitt enxergou rapidamente uma oportunidade de estabelecer uma conexão entre o Tibete e Darfur, sob o grande guarda-chuva de "genocídio", pois agora havia pessoas visivelmente sob o controle da opressão chinesa. Ao mesmo tempo, outros atores, como Sarkozy da França, a delegada de Direitos Humanos da UE,
Louise Barber, o Parlamento da UE e Hillary Clinton assumiram atitudes que melhoraram a posição de Savitt e que lhe garantiram credibilidade. No final de março, até mesmo o International Herald Tribune tinha dedicado um artigo com sete colunas sobre as atividades de sua organização.

Essa foi simplesmente uma conjuntura casual, porém esse é meu ponto principal, que ilustra como a sociedade civil pode se desenvolver não por intermédio dos esforços dessa ou daquela conferência internacional ou ONG, nem porque The Economist ou o FMI exige uma agenda neoliberal, mas graças a cosmopolitas enraizados, disponíveis para ligar eventos não conectados a campanhas frouxamente conectadas. Pode parecer uma nota pessimista para os que trabalham no mundo frustrante dos direitos humanos transnacionais, mas não é essa minha intenção. Ao fazer com que os atores nacionais entrem em contato com as instituições internacionais e atores trasnacionais, esses processos viabilizam a criação de uma classe de cosmopolitas enraizados, que pode intermediar os vínculos entre as arenas nacionais e internacionais, familiarizando os atores domésticos com a arena internacional e legitimando o envolvimento dos atores internacionais na esfera nacional.

É bem provável que essa transferência não seja surpreendente ou completa. Vamos levar em conta o que Merry escreve sobre as idéias de direitos humanos em relação à violência contra as mulheres: elas são infiltradas nas comunidades locais de forma fragmentada e limitada, "basicamente pela mediação de ativistas que traduzem a linguagem local em termos locais relevantes" (Merry, 2006, p. 218). Entretanto, para quem já enfrentou o peso da tradição, da burocracia e da obstrução, trabalhando no mundo da ação transnacional, essa tradução é uma etapa significativa rumo à construção de um mundo mais humano e semelhante.

Tradução: Maria Lavínia Sobreira de Magalhães Revisão Técnica: Breno Bringel

(Recebido para publicação em outubro de 2008) (Aceito em dezembro de 2008) 


\section{REFERÊNCIAS}

ALTER, Karen; VARGAS, Jeannette. Explaining variation in the use of European litigation strategies: EC law and UK gender equality policy. Comparative Political Studies, Oxford,UK, Sage, v. 33, p. 452-482, 2000.

BALME, Richard; CHABANET, Didier. European governance and democracy: protest and power in the EU. Lanhma MD: Rowman and Littlefield, 2008.

BENNETT, Lance. Communicating global activism. Information, Communication and Society, New York, Routledge, v. 6, p. 143-168, 2003.

BOHLE, Dorothee; GRESKOVITS, Béla. Neoliberalism embedded neoliberalism and neocorporatism: paths towards transnational capitalism in Central-Eastern Europe. West European Politics, New York, Routldge, v. 30, p. 443-466, 2007. Disponível em: http://econ.core.hu/ doc/seminar/Bohle-Greskovits WEP Final.doc

BUNCE, Valerie; WOLCHIK, Sharon Wolchik International diffusion and postcommunist electora revolutions. Journal of Communist and Postcommunis Studies, The Johns Hopkins University Press, v. 39, p. 283-304, 2006

CAPORASO, James; JUPILLE, Joseph. The europeanization of gender equality policy and domestic structural change. In: COWLES, Maria Green CAPORASO, James; RISSE, Thomas (Ed.) Transforming Europe: europeanization and domestic change. Ithaca/ London: Cornell University Press, 2001

CHABANET, Didier. Les marches européenes contre le chômage, la précarité et les exclusions. In: BLAME, Richard; CHABANET, Didier; WRIGHT, Vincent. L'action collective en Europe. Paris: Presses de Sciences Po, p. 461 493, 2002.

CHICOWSKI, Rachel. Judicial rulemaking and the institutionalization of the European Union sex policy. In: STONE, Alex; FLIGSTEIN, Neil; SANDHOLTZ, Wayn (Ed.). The institutionalization of Europe. Oxford: Oxford University Press, 2001.

GIRAUD, Baptiste; GARCIA, Guillaume; MOUCHARD Daniel YON, Karel. La question sociale au Forum social. In: AGRIKOLIANSKY, Eric; SOMMIER, Isabelle (Ed.) Radiographie du mouvement altermondialiste. Paris: La Dispute, 2005. protesters respond to the september 11 terrorist attacks: the impact of an intentional disaster on demonstrations in Washington D.C. Beyond september 11: an account of post-disaster research. Boulder CO: Natural Hazards Research and Information Center, 2003. p. 483-520,

HADDEN, Jennifer; TARROW, Sidney. The global justice movement in the United States since seattle. In: DELLA PORTA, Donatella (Ed.) The Global justice movement. Boulder CO: Paradigm Press, 2007a.

Spillover or spillout: The global justice movement in the United States after 9/11. Mobilization: an international quaterly, [S.l.], v. 12, n. 4, p. 359-376, $2007 \mathrm{~b}$.

HALL, Peter; TARROW, Sidney. Globalisation and area studies: when is too broad too narrow? Chronicle of Higher Education, Oklahoma, winter B4-B5, 1998.

HAYNER, Priscilla. Unspeakable truths: facing the challenge of truth commissions. New York: Routledge, 2006.

HELFFERISCH, Barbara; KOLB, Felix. Multilevel action coordination in European contentious politics: the case of the European women's lobby. In: IMIG, Doug;
TARROW, Sidney (Ed.) Contentious Europeans: protest and politics in an emerging polity. Lanham MD: Rowman and Littlefield, 2001.

IMIG, Doug; TARROW, Sidney. Mapping the europeanization of contention. In: IMIG, Doug; TARROW, Sidney (Ed.) Contentious Europeans: protest and politics in an emerging polity. Lanham MD: Rowman and Littlefield, 2001.

KECK, Margaret; SIKKINK, Kathryn. Activists beyond borders: advocacy networks in international politics. Ithaca: Cornell University Press, 1998.

MERRY, Sally Engle. Human rights and gender violence: translating international law into local justice. Chicago: University of Chicago Press, 2006.

NOAKES, John; KLOCKE, Biran; GILLAM, Patrick. Whose streets? Police and protesters struggle over space in Washington DC, 29-30 september, 2001. Policing and Society, New York, Routlege, n. 15, p. 235-254, 2005.

REITAN, Ruth. Constructing the world's other superpower: antiwar movements go global to counter us global war on terror. In. UNPUBLISHED PAPER PRESENTED TO THE INTERNATIONAL STUDIES ASSOCIATION. Chicago, february, 2007.

ROBERTS, Kenneth. Repoliticizing Latin America: the revival of populist and leftist alternatives. Woodrow Wilson Center Update on the Americas, Washington,D.C. Woodrow Wilson Center for Scholars. Latin American Program, nov., 2007. Disponível em: www.wilsoncenter. org/topics/pubs/repoliticizing.roberts.lap.pdf

The mobilization of opposition to economic liberalization. Annual Review of Political Science, Washington, D.C., n. 11, 2008. Forthcoming.

SCHATTLE, Hans. The practices of global citizenship. Lanham MD: Rowman \& Littlefield, 2008.

SIKKINK, Kathryn. Patterns of dynamic multilevel governance and the insider-outsider coalition. In: DELLA PORTA, Donatella; TARROW, Sidney (Ed.) Transnational protest and global activism. Lanham MD: Rowman and Littlefield, 2005.

SKLAIR, Leslie. The transnational capitalist class. Oxford: Blackwell, 2001.

TARROW, Sidney. The new transnational activism. New York: Cambridge University Press, 2005.

TSUTSUI, Kiyoteru; SHIN, Hwa-Ji. Global norms, local activism, and social movement outcomes: global human rights and resident Koreans in Japan. Social Problems, University of California Press, v. 55, n.3, 2008. Disponível em http://caliber.ucpress. net/doi/abs/10.1525/ sp.2008.55.3.391 


\section{OUTISIDERS INSIDE AND INSIDERS OUTSIDE: linking transnational and domestic public action for human rights}

\author{
Sidney Tarrow
}

Is the growth of a global civil society a cumulative process, or are we only seeing occasional transnational outcroppings in a sea of states? To put this question more broadly: "Is the traditional divide between domestic and international politics breaking down?" On this question much of the future of transnational social movement activism depends. I will first illustrate the dilemma with a story that is both current and familiar; the Olympic Torch protests in London and Paris and its connections to Tibet and Darfur, for what it tells us about the nature of transnational public activism. I will then construct a typology of forms of domestic/transnational interaction among non-state public actors; I will then turn - with some trepidation - to a prediction about the future of what some have called "global civil society" and how it may affect transnational activism.

KEY-WORDS: transnational activism, social movements, global civil society, comparative politics, non-state public actors.
OUTSIDERS INSIDE et insiders outside: entre l'action publique nationale et transnationale en faveur des droits de l'homme

\author{
Sidney Tarrow
}

La croissance d'une société civile globale est-elle un processus cumulatif ou sommes-nous seulement en présence de l'affleurement transnational d'une série d'Etats? Pour poser cette question de manière plus générale: La division traditionnelle entre politiques nationales et internationales est-elle en train de se décomposer? L'avenir de l'activisme social et transnational dépend en grande partie de cette question. Dans cet article, nous illustrerons tout d'abord ce dilemme en nous rapportant à l'histoire actuelle, connue: les protestations liées à la Flamme Olympique, à Londres et à Paris, et leurs rapports avec le Tibet et le Darfour, en cherchant à savoir ce que cela signifie par rapport à la nature de l'activisme transnational public. Ensuite, nous construirons une typologie des formes d'interaction nationale et transnationale entre les acteurs publics qui n'appartiennent pas à l'état. Ultérieurement nous projèterons l'avenir, avec une certaine prudence, de ce que certains appellent la "société civile globale" et de la manière dont elle peut marquer l'activisme transnational.

Mots-CLÉs: activisme transnational, mouvements sociaux, société civile globale, politique comparative, acteurs publics qui n’appartiennent pas à l'état.

Sidney Tarrow - Professor da Cátedra Maxwell Upson de Governo e Sociologia do Departamento de Sociologia da Universidade de Cornell (Estados Unidos). PhD em Sociologia pela Universidade de Berkeley (Califórnia, 1965). Pesquisa, há décadas, os movimentos sociais e de ação coletiva. Seu livro Democracy and Disorder (Oxford, 1989) recebeu o Prêmio de melhor livro sobre Ação Coletiva e Movimentos Sociais da Associação Americana de Sociologia. Seu livro mais importante é Power in Movement (Cambridge, 1994, $1^{\mathrm{a}}$ edição), traduzido para o espanhol e chinês. É coautor de livros importantes como a Dynamics of Contention (Cambridge, 2001, com Doug McAdam e Charles Tilly) e Contentious Politics (Paradigm, 2006, com Charles Tilly). Em 2005, publicou o livro The New Transnational Activism (Cambridge, 2005) e têm publicado vários artigos em conceituadas revistas internacionais. 
